\title{
Neuraxial block for EXIT procedure (ex utero intrapartum treatment) - A case report and literature review
}

\author{
Patricia M. Garza-Gutiérrez, Gustavo Millán-Cornejo, Gabriela A. Vázquez-Guerra, \\ Belia Inés Garduño-Chávez* and Dionicio Palacios-Ríos \\ Anesthesiology Service, Dr. José Eleuterio González University Hospital, Universidad Autónoma de Nuevo León, Monterrey, N.L., Mexico
}

\begin{abstract}
Introduction: The ex utero intrapartum treatment (EXIT) involves the partial removal of the fetus from the uterine cavity during a cesarean section while maintaining placental circulation and oxygenation. This procedure is indicated when we expect a difficult access to the respiratory airway. Clinical Case: A 33-year-old female patient, with 35.4 weeks of pregnancy and a diagnosis of placenta accreta and a fetus with Bochdaleck's diaphragmatic hernia diagnosed by prenatal ultrasound, was scheduled for elective cesarean with the EXIT procedure. The chosen anesthetic technique for the patient was neuraxial anesthesia. Conclusion: The EXIT procedure is a challenge for the anesthesiologist, and they should be aware and prepared for the physiological changes of pregnancy and uteroplacental physiology. This case demonstrates that even though the preferred technique in the EXIT procedure is general anesthesia, it can also be performed effectively and safely under a neuraxial technique with invasive monitoring.
\end{abstract}

Key words: Ex utero intrapartum treatment procedure. Obstetric anesthesia. Neuraxial technique. Congenital malformations.

\section{Introduction}

The "ex utero intrapartum treatment" (EXIT) consists of the partial extraction of the fetus from the uterine cavity through a $\mathrm{C}$-section procedure while circulation and oxygenation are maintained through the placenta. This is indicated when difficulties in airways are detected, as in the case of airway anomalies and/or congenital malformations ${ }^{1}$. This procedure was first described in the late 1980s for the treatment of patients with a large head and neck malformations and a high potential for difficult airway management, although back then it was known as fetal surgery with placental bypass ${ }^{2,3}$. Today, indications for EXIT are on the rise, and its anesthetic management varies between balanced general anesthesia and a neuraxial block. We present a case report of a patient at the "Dr. Jose E. González" University Hospital at the Autonomous University of Nuevo Leon (UANL by its Spanish acronym) who underwent an EXIT procedure under neuraxial blockade.

\section{Clinical case}

A 33-year-old female, with a body mass index of 28.9, multiple gestations (1 C-section and one interrupted), 35.6 weeks pregnant, attended for an elective $\mathrm{C}$-section, with a diagnosis of placenta accreta and a fetus with a Bochdaleck's diaphragmatic hernia diagnosed by prenatal ultrasound. The decision to perform

\section{Correspondence:}

Belia Inés Garduño-Chávez

E-mail: beliagarduno64@gmail.com
Date of reception: 03-07-2018

Date of acceptance: 06-09-2018

DOI: 10.24875/RMU.M18000023
Available online: $30-11-2018$
Medicina Universitaria. 2018;20(3): 129-132
www.medicinauniversitaria.org www.medicinauniversitaria.org CC BY-NC-ND license (http://creativecommons.org/licenses/by-nc-nd/4.0/). 
the EXIT procedure was made by the obstetric and pediatric services working together, as a result of the severity of the case. A day before the procedure, a pre-operative assessment was performed by the anesthesiology service, where they found two previous surgeries in the patient's history (cholecystectomy and gastric sleeve). No further findings of pathological data which might interfere with the surgical procedure were reported in the rest of the questionnaire, physical exploration, and laboratory work (Table 1).

The decision to put the patient under a continuous epidural blockade and intravenous (IV) sedation was made on the day of the surgery. Previous to the epidural blockade, the patient was medicated with ranitidine $50 \mathrm{mg}$, metoclopramide $8 \mathrm{mg}$, dexamethasone $10 \mathrm{mg}$, and prophylactic antibiotic therapy with $2 \mathrm{~g}$ of cephalothin, all intravenously. Once monitored, a radial arterial line was placed before local anesthesia and was maintained with supplementary oxygen using a face mask at $5 \mathrm{~L} / \mathrm{min}$. Subsequently, the patient was placed adequately to have a left uterine displacement. Furthermore, $400 \mathrm{mg}$ of lidocaine with epinephrine was applied through an epidural. Contemplating abundant bleeding caused by placental acretism, the patient was pre-hydrated with $3000 \mathrm{ml}$ of Hartmann's solution before the extraction of the product. To accomplish an adequate sedation on the product and perform the EXIT procedure satisfactorily, IV sedation with fentanyl $300 \mathrm{mcg}$ and midazolam $3.5 \mathrm{mg}$ was administered previous to the uterotomy without causing the patient a respiratory depression nor compromising maternal airways. Subsequently, three rescue doses of IV ephedrine $5 \mathrm{mg}$ were required to maintain mean blood pressure $(\geq 65 \mathrm{mmHg}$ ) on the patient. After an adequate uterine relaxation was confirmed, the uterotomy took place, extracting the product partially and intubating it by the neonatologist through a direct laryngoscopy using a Miller blade 0 . Subsequently, the umbilical cord was clamped to continue with the surgical procedure as planned and the product went on to the intensive care unit.

Since the plan was a hysterectomy due to a placenta accreta, no oxytocin was administered to have an adequate uterine relaxation, thus avoiding abruptio placentae. The surgical procedure concluded with a total bleeding of $3400 \mathrm{ml}$. Consequently, during the entire procedure, the patient was sustained with $1000 \mathrm{ml}$ of colloid solution, $5000 \mathrm{ml}$ of crystalloid solution, five packed red cell transfusions, four packs of plasma, and four packs of platelet concentrates, keeping the patient hemodynamically stable during the entire surgery, with
Table 1. Cabinet studies of the patient before neuraxial block for the EXIT procedure.

\begin{tabular}{|l|c|c|}
\hline Study & Result & \multicolumn{1}{|c|}{ Reference values } \\
\hline Blood count & & \\
HGB & $11 \mathrm{~g} / \mathrm{dL}$ & $12.2-18.1$ \\
HCT & $34.9 \%$ & $37.7-53.7$ \\
MCV & $89.9 \mathrm{fL}$ & $80-97$ \\
MCH & $28.3 \mathrm{Pg}$ & $27-31.2$ \\
MCHC & $31.4 \mathrm{~g} / \mathrm{dL}$ & $29.9-34.2$ \\
WBC & $9.25 \mathrm{~K} / \mathrm{uL}$ & $4-11$ \\
NEU & $5.91 \mathrm{~K} / \mathrm{uL}$ & $2-6.9$ \\
LYM & $2.65 \mathrm{~K} / \mathrm{uL}$ & $0.6-3.4$ \\
EOS & $0.105 \mathrm{~K} / \mathrm{uL}$ & $0-0.7$ \\
BASO & $0.066 \mathrm{~K} / \mathrm{uL}$ & $0-0.2$ \\
PLT & $192 \mathrm{~K} / \mathrm{uL}$ & $142-424$ \\
\hline Coagulation times & & \\
TP & $11.4 \mathrm{Seg}$ & $9.9-12.3$ \\
Control & $11.3 \mathrm{Seg}$ & \\
INR & 1.03 & \\
Control & 1.02 & $25.2-36$ \\
\hline TTP & $32.1 \mathrm{Seg}$ & \\
Control & $30.4 \mathrm{Seg}$ & \\
\hline Clinical chemistry & & \\
GLU in blood & $75 \mathrm{mg} / \mathrm{dL}$ & $60-100$ \\
\hline BUN in blood & $9 \mathrm{mg} / \mathrm{dL}$ & $7-20$ \\
\hline Cr in blood & $0.4 \mathrm{mg} / \mathrm{dL}$ & $0.6-1.4$ \\
\hline B. & \\
\hline
\end{tabular}

HGB: hemoglobin, HCT: hematocrit, MCV: mean corpuscular volumen, $\mathrm{MCH}$ : mean corpuscular hemoglobin, MCHC: mean corpuscular hemoglobin concentration, WBC: white blood cells, NEU: neutrophils, LYM: lymphocytes, EOS: eosinophils, BASO: basophils, PLT: platelet, TP: total protein, TTP: thrombotic thrombocytopenic purpura, GLU: glucose, BUN: blood urea nitrogen, Cr: creatinine.

a surgical time of $4 \mathrm{~h}$. It is worth noting that the total amount of time from the incision of the skin to the hysterectomy was 54 min and the total amount of time from the amniotomy until full delivery of the product was $8 \mathrm{~min}$. The patient was placed in the post-surgical recovery room without complications, and morphine $1.4 \mathrm{mg}$ was utilized epidurally for post-operative pain management.

\section{Discussion}

The EXIT is a technique designed to establish a safe airway during delivery in products with risk of airway obstruction or congenital malformations, securing the airway through a laryngoscopy, fibroscopy, or tracheostomy before placenta-fetal separation. This consists of maintaining maternal-fetal oxygenation, without umbilical cord section, and controlling the obstruction while a new permeable airway is created ${ }^{4,5}$. This procedure has been described as harmless for up to $60 \mathrm{~min}$; however, there are reports of cases with a longer duration without complications, neither for the mother nor the product ${ }^{4}$. Anesthetic goals for this 
procedure include having a proper uterine relaxation, fetal anesthesia for airway manipulation, and maintaining a permeable maternal-fetal circulation ${ }^{6}$. Anesthetic management of patients who undergo this procedure has also evolved, with a variety of strategies described in the literature. The ideal technique for the EXIT procedure is a C-section under general anesthesia, accomplishing a uterine relaxation with tocolytics such as magnesium sulfate or nitroglycerin and with aggressive management of liquids or vasopressors to avoid hemodynamic instability? ${ }^{7}$ Nevertheless, neuraxial anesthesia can also be considered, always keeping in mind the most common complication, which is bleeding linked to uterine atony caused by the administration of tocolytics ${ }^{8,9}$. Regardless of the technique used, invasive monitoring is highly recommended to have proper control of the patient and the product $7,8,10,11$.

To be able to perform an EXIT procedure successfully, it is necessary to accomplish proper fetal anesthesia to have an adequate handling of the airways. This is achieved with transplacental anesthetic agents previously administered to the patient ${ }^{12}$. In case of suboptimal anesthesia, this can be handled with IV or intramuscular medications directly on the fetus ${ }^{7,8,11}$. The anesthetic management of choice in our case was neuraxial anesthesia, obtaining favorable results. Even though this technique is not the golden choice for this type of procedure, there are reports of previous cases where this technique was utilized with satisfactory results $1,7,9,13$, This reduces the risk of bronchoaspiration and failure in intubation, which are the most frequent complications that general anesthesia brings to the table ${ }^{14}$. In our case, a proper uterine relaxation was accomplished without the need to utilize tocolytic agents, maintaining a systolic pressure of $>129 \mathrm{mmHg}$ in the patient (with the use of ephedrine, crystalloids, and colloids) and accomplishing placental profusion.

In a study by Miyakoshi et al., safe administration of IV sedation in obstetric patients was reported ${ }^{15}$. In our case, we too were able to accomplish proper sedation without hypoventilating the patient nor compromising the airways. Moreover, fetal sedation was achieved and verified through the absence of reaction during direct laryngoscopy and orotracheal intubation, due to the transference of anesthetic agents previously administered through maternal circulation.

Usually, $10 \mathrm{UI}$ (range 3-40 UI) of oxytocin is administered to avoid uterine atony and postpartum hemorrhage ${ }^{16}$. Due to the complexity of our case, where the plan was to perform a hysterectomy for placenta accreta, the decision to not administer this medication on the patient was made by the obstetrics and anesthesiology services, thus avoiding placenta abruption. Although there was more bleeding than that estimated in a conventional C-section $(3400 \mathrm{ml})$, management with ephedrine, hemoderivatives, crystalloids, and colloids was enough to keep the patient thermodynamically stable.

\section{Conclusion}

The EXIT procedure is a technique which is increasingly being used for congenital fetal anomaly treatment during delivery. These cases represent a challenge for the anesthesiologist and require a deep understanding of the physiological changes of pregnancy, placenta-uterus physiology, and the effects of the selected pharmacological agents. Uterine relaxation, uteroplacenta perfusion maintenance, and maternal-fetal cardiovascular compromise prevention are key factors to consider during this procedure. These cases show that although the technique of choice for the EXIT procedure is general anesthesia, we could also perform it effectively and safely under a neuraxial blockade with invasive monitoring.

\section{Conflicts of interest}

The authors declare not to have any conflicts of interest.

\section{Financing}

There was no financial support.

\section{Ethical disclosures}

Protection of human and animal subjects. The authors declare that no experiments were performed on humans or animals for this study.

Confidentiality of data. The authors declare that no patient data appear in this article.

To privacy and informed consent. The authors have obtained the written informed consent of the patients or subjects mentioned in the article. The corresponding author is in possession of this document.

\section{References}

1. Braden A, Maani C, Nagy C. Anesthetic management of an ex utero intrapartum treatment procedure: a novel balanced approach. J Clin Anesth. 2016;31:60-3.

2. Levine AB, Alvarez M, Wedgwood J, Berkowitz RL, Holzman I. Contemporary management of a potentially lethal fetal anomaly: a successful perinatal approach to epignathus. Obstet Gynecol. 1990;76:962-6. 
3. Schwartz MZ, Silver H, Schulman S. Maintenance of the placental circulation to evaluate and treat an infant with massive head and neck hemangioma. J Pediatr Surg. 1993;28:520-2.

4. Acosta CC, Martínez GE, López JA et al. Epignato: teratoma orofaríngeo: comunicación de un caso. Med Univ. 2009;11:129-33.

5. Hullett BJ, Shine NP, Chambers NA. Airway management of three cases of congenital cervical teratoma. Paediatr Anaesth. 2006;16:794-8.

6. Kuczkowski KM. Advances in obstetric anesthesia: anesthesia for fetal intrapartum operations on placental support. J Anesth. 2007;21:243-51.

7. Oliveira E, Pereira P, Retroz C, Mártires E. Anesthesia for EXIT procedure (ex utero intrapartum treatment) in congenital cervical malformation-a challenge to the anesthesiologist. Braz J Anesthesiol. 2015;65: 529-33.

8. De Buck F, Deprest J, Van de Velde M. Anesthesia for fetal surgery. Curr Opin Anaesthesiol. 2008;21:293-7.

9. George RB, Melnick AH, Rose EC, Habib AS. Case series: combined spinal epidural anesthesia for cesarean delivery and ex utero intrapartum treatment procedure. Can J Anaesth. 2007;54:218-22.
10. Botto HA, Boailchuk ID, García C, et al. Ex utero intrapartum treatment-management of neonatal congenital high airway obstruction syndrome: case report. Arch Argent Pediatr. 2010;108:e92-5.

11. Marwan A, Crombleholme TM. The EXIT procedure: principles, pitfalls, and progress. Semin Pediatr Surg. 2006;15:107-15.

12. Casini EA. Pasaje transplacentario de drogas. Rev Argent Anestesiol. 2000;58:345-57.

13. Zadra N, Meneghini L, Midrio $\mathrm{P}$, et al. Ex utero intrapartum technique. Minerva Anestesiol. 2004;70:379-85.

14. Hawkins JL, Chang J, Palmer SK, Gibbs CP, Callaghan WM. Anesthesia-related maternal mortality in the United States: 1979-2002. Obstet Gynecol. 2011;117:69-74.

15. Miyakoshi K, Tanaka M, Morisaki H, et al. Perinatal outcomes: intravenous patient-controlled fentanyl versus no analgesia in labor. $\mathrm{J}$ Obstet Gynaecol Res. 2013;39:783-9.

16. Schiraldi R, Guasch E. Oxytocin for the prophylaxis of uterine atony after cesarean delivery. Should we reconsider our protocols? Rev Esp Anestesiol Reanim. 2014;61:359-61. 